Volume 27, 2017

http://journals.sfu.ca/cjsdw

Article

\title{
What a Generalist Tutor Can Do: A Short Lesson from a Tutoring Session
}

Tomoyo Okuda

University of British Columbia

\section{Introduction: Specialist and Generalist Tutoring}

In parallel to the unique history of writing instruction, Canadian writing specialists have drawn on different theories and principles from the U.S. literature in building their writing studies scholarship (Giltrow, 2016; Graves, 1993; Graves \& Graves, 2006; Paré, 2017; Smith, 2006). This is evident in the "Statement on Writing Centres and Staffing" published by the Canadian Journal for Studies of Discourse and Writing (Graves, 2016). As a doctoral student researching U.S.-based writing centres from day one of graduate school, one striking cross-border difference I find was the statement's clear recommendation that writing centres are fundamentally teaching units in which students learn to write in their disciplines. In American writing centre theory, peer tutoring is the basis of writing centre philosophy, with some claiming that the tutor's unfamiliarity of the tutee's discipline enhances the non-hierarchical learning environment (Bruffee, 1995; North, 1984; Pemberton, 1995).

Learning how to write in one's discipline is certainly crucial in academic studies, especially in graduate school where students are trained to become experts in their field. In Canada, there are some specialist writing centres that consult students on specific course assignments and specific disciplines (e.g., University of Toronto). Discipline-specific writing support can be made possible by setting up a writing support system in respective departments, pairing tutors and tutees in the same discipline, and implementing curriculum-based tutoring in which tutors collaborate with course instructors and work with students on specific assignments (e.g., Mohamad \& Boyd, 2010; Walker, 2000). A number of studies also support the role of disciplinary expertise in writing centre tutoring; tutors familiar with disciplinary expectations could help facilitate tutoring sessions better, while tutors' lack of disciplinary knowledge can lead them to not push back on students' claims, make inaccurate suggestions incongruent with 
Volume 27, 2017

http://journals.sfu.ca/cjsdw

the discipline, and express mistaken expectations of the genre (Dinitz \& Harrington, 2014; Kiedaisch \& Dinitz, 1993; Mackiewicz, 2004).

However, the common model of Canadian writing centres seems to be generalist tutoring, rather than specialist tutoring (although the terms generalist and specialist would imply there is no middle ground, which is certainly not the case, these terms are used in this paper as a heuristic to understand the unique nature of writing centre tutoring). In generalist tutoring models, undergraduate and graduate students are trained in general writing strategies that help improve the process of writing. Out of the 26 Anglophone Canadian universities categorized as research and comprehensive universities (see http://www.accru.ca/ and u15.ca for a list of universities), only five universities explicitly state on their websites that they offer disciplinespecific tutoring. Although many universities do seem to have separate appointments for their graduate students, which might include disciplinary research support, the common mission of most Canadian writing centers is generalist in nature: to help students at all levels in any discipline and in any stages of the writing process.

Although the ideal writing centre is upheld by the "Statement" as a discipline-specific teaching unit, this remains only an ideal if we do not look into what really happens in tutoring sessions in Canadian universities. In addition to pushing forward discipline-specific writing support, it is also important to examine our common practices in depth and how they could complement more specialized writing support; namely, in what specific ways can generalist tutors, who may not be familiar with writing outside of their own fields, help student writers in any discipline and any level of study. In the hope of making a small but relevant contribution, this paper analyses excerpts from a transcript of a generalist tutoring session at a Canadian university in which Catherine (a pseudonym), an fourth-year undergraduate tutor majoring in international relations helps Xiaoli (also a pseudonym), a second-year master's student in education, overcome her writer's block.

The data collection for this tutoring session was conducted as a pilot study of my dissertation research. Research questions were: (1) What kind of tutoring strategies did the tutor use? and (2) How did the tutee perceive their tutoring sessions?

A few days after the director of the writing centre at the university described my study to the tutors, Catherine contacted me and invited me to observe her sessions. Catherine had been tutoring at the writing center for three years, making her one of the most experienced tutors in the centre. According to Catherine, the tutors received training on basic procedures of tutoring sessions and tutoring strategies at the beginning of the term. Since I could not find tutee 
Volume 27, 2017

http://journals.sfu.ca/cjsdw

participants through invitation letters, I used personal contacts and found Xiaoli, who agreed to participate in my study.

Xiaoli first reserved the writing centre's 20-minute drop-in session when Catherine was on duty. I observed and audio-recorded their session, and later interviewed both Catherine and Xiaoli. In my interview with Catherine, I asked about her intentions behind tutoring strategies and her beliefs about writing centre philosophy. The aim of my interview with Xiaoli was to inquire into her perceptions about the writing centre tutorial (feedback, tutoring strategies, writing centre pedagogy, tutor's expertise) and any benefits and drawbacks of the writing centre as a viable method of writing support. Data was analyzed by of identifying themes based on my research questions.

In analyzing both session interactions and post-tutorial interviews, I was able to learn more about what worked and did not work for Xiaoli in this particular generalist tutoring session, which points to one of the pedagogical roles that generalist tutoring plays in supporting graduate students' academic literacy practices.. In this short analysis, I will focus on tutor-tutee interactions and reflections concerning two types of tutor feedback: "free-writing" and "Istatement”.

\section{Free-writing}

Xiaoli, a regular visitor of the writing centre, came to the writing centre drop-in session to discuss the content of the literature review of her Master's thesis. Her thesis topic was on the interrelations between pop culture, identity, and second language learning. Xiaoli was about to write her literature review but was struggling with different concepts in the literature and was experiencing writer's block. She came to the writing centre for advice on how to organize her literature review section. Right after the brainstorming session started, she started to enthusiastically talk about the different types of identities she had read about. She did not know what to include and how to tie things together. After a while, she sought Catherine's opinion. Catherine responded by recommending a writing strategy (highlighted in bold):

Xiaoli: I just can't write until I understand the relationship. Do I only mention this part or only this part? Or how can I... 
Volume 27, 2017

http://journals.sfu.ca/cjsdw

Catherine: Well, they both sound important. Yeah...and interesting. The way you explain they seem really connected to the data that you produced. I think they're worth exploring how to include for sure. Um...

Xiaoli: $\quad$ Shall we say first step and second step? So maybe I'll argue that when students form a habit of regular engagement with Chinese pop culture and then they are constructing this identity first, so, at least they appreciate aesthete, this intellectual discrepant identity.

Catherine: Have you tried writing about each one separately?

Xiaoli: $\quad$ So, you mean I write them down separately and think?

Catherine: Well because sometimes when you put things down on paper, put them into words and start expanding on your ideas and making connections to your data and really writing it out? You'll see connections that you haven't thought of before, the process of writing things down is itself part of the thinking process. So um, yea, if you're having writer's block because you can't figure out how to make them mesh in a way that's logical, just keep them separate for now. If there's like a wall in your mind, that's fine, keep them separate and as you write, maybe something will click.

Xiaoli: OK.

(Tutoring session, 03/19/2015)

Instead of offering her opinion, Catherine suggested that Xiaoli write down each idea on a piece of paper and figure out the relationship-a strategy called free-writing. When I interviewed her, Xiaoli told me that she was showing respect to her tutor by telling her that she would try free-writing. Xiaoli expressed that showing respect to her tutor's suggestions is key in building a relationship of trust. Despite Catherine's advice, however, Xiaoli considered the free writing strategy not useful for her:

Okuda: Was this advice helpful to you?

Xiaoli: If it's my first [time] to hear that kind of tips, it would be helpful. Because if students don't know what are some practical skills, they need to get over writer's block, then this advice is write on no matter what, don't care about grammar, structure, just write down your ideas and 
Volume 27, 2017

http://journals.sfu.ca/cjsdw

then you might find a clue. But you see this kind of suggestion can be used on a student only once. If I could [come to the centre] ten times and every time [the tutor] said just write down your ideas, you'll find yourself. Then why do I have to come to you and discuss?

(Interview with Xiaoli, 03/31/2015)

Xiaoli's reflections point to pitfalls of universal tutoring strategies introduced in tutoring manuals. As a frequent writing centre visitor, Xiaoli did not want to hear the same generic writing tips about improving her writing process. She later reflected in the interview that she even sensed Catherine not wanting to discuss the content of her thesis, as Catherine redirected the focus to writing strategies. Instead of receiving writing tips, it became evident that Xiaoli came to the writing centre for a different purpose, demonstrated in the next section.

\section{"I-Statement"}

In contrast to her general writing advice, there were times in the session when Catherine focused more on the content of Xiaoli's ideas. Here, she presented her understanding of the relationship between "intellectual identity" and "personal identity" which Xiaoli explained to her beforehand:

Catherine: That's really interesting, cool, hmmm...So you're struggling to sort of...

Xiaoli: $\quad$ Figure out, try to maybe have a tree map [of] which happened first and then and what.

Catherine: Well, um, the way I understand it is that the unifying factor is identity, it's all about identity obviously, and you have on one side an idea of intellectual identity or artistic identity and then on the other side personal identity so...

Xiaoli: $\quad$ So you think this is personal identity? And then this is artistic identity?

Catherine: Yea, and the...the artistic identity is something that you construct sort of and the personal identity, well, it's the way you are. Right? You're...the idea that the narrative, demographic and mood it's based on your lived experience, right? It's not something you have total control over 
Volume 27, 2017

http://journals.sfu.ca/cjsdw

Catherine gave her interpretation of what she understood from Xiaoli's ideas and the literature ("the way I understand it is that..."), which she explained using an "I-Statement" strategy. According to Catherine, the purpose of this strategy is to inform the student what the tutor "understands them to be doing" so students can see a new connection or perspective. In contrast to the free writing strategy, this turned out to be a successful strategy for Xiaoli, as she reported when I interviewed her:

Usually my impression of writing centre tutors from my past experience, except my favorite tutor, others are very passive, so they do not contribute much and here I appreciate her that she contributes her personal creative thinking. It shows that she is genuinely trying to help me find a clue to understand my problems. So she is contributing her creative thinking. She suggests, how about using identity to understand these things. I really appreciate that. (Interview with Xiaoli, 03/31/2015)

Although Catherine was paraphrasing what Xiaoli said during the tutoring session, Xiaoli saw it as her contributing her own ideas, which she describes as "personal creative thinking."

Another "personal creative thinking" moment was observed when Xiaoli started to talk about the concept of "labor" in media consumption and saw that it might also be important to her literature review. Catherine saw a connection between labor and previous discussions about identity (highlighted in bold):

Catherine: So do you maybe see this labor to understand another culture? Could there

\section{be a labor involved in performing one's identity and in understanding one's identity?}

Xiaoli: What do you mean? That's interesting.

Catherine: Well, if there's effort, there's work going on to understand this culture, could there simultaneously be some kind of conscious effort, conscious work to define or redefine yourself through language learning?

Xiaoli: Let's write this down this sentence, this is very interesting. Can you say it again?

Catherine: Uh...I'll try? If there's a labor going on to um, understand another culture as 
Volume 27, 2017

http://journals.sfu.ca/cjsdw

an aesthete or whatever, expert, artist, etcetera...could they also be labor involved...in self-identification or the performance of identity?

Xiaoli: $\quad$ Um in the first time you said could there be conscious labor, right?

Catherine: Umm-hmm.

Xiaoli: $\quad$ Because in these two cases, it's consciously.

Catherine: Yeah.

Xiaoli: Because people realize they identify with their heritage identity. They embrace their marginalized identity. So it's conscious labor in performance of identity.

Catherine: Yes. That could be connection?

Xiaoli: $\quad$ How? So this is more general and this is a small part of it?

Catherine: It could be? Yeah. That it's all intellectual labor and self-identification could be part of the labor?

(Tutoring session, 03/19/2015)

As her use of "could" suggests, Catherine tried not to give definite answers but presented possible connections. After she did, Xiaoli became excited and wanted to hear more about this new connection of concepts. In my interview with her, Xiaoli described this interaction as the highlight of the session, motivating her to further pursue the connection in literature.

This is the highlight of the whole conversation and I'm really learning from her. This part, she inspired me to think about labor and identity and now today I have developed better understanding because after this conversation, I went back to look up literature on labor, intellectual labor, media conception, and I found what I wanted to find so I could build up my argument much better, based on her suggestion. So this is very creative thinking here, and she really makes contributions.

(Interview with Xiaoli, 03/31/2015)

Catherine reflected that she was also happy to see Xiaoli's excitement. For the rest of the session, Xiaoli talked about how she could organize her literature review based on previous discussions and Catherine clarified or rephrased what Xiaoli said.

Although Xiaoli said that Catherine made contributions by offering her ideas, when I interviewed Catherine, she did not describe it this way. Rather, she said she was paraphrasing or 
Volume 27, 2017

http://journals.sfu.ca/cjsdw

pointing to connections that were already in the student's draft, which she differentiated from giving ideas.

I don't just give my ideas. I definitely spend a lot of time paraphrasing students' work though. Sometimes to them it suddenly sounds like a new idea, but it's like well I thought that was idea already you had written down there, but maybe it's not.

(Interview with Catherine, 03/30/2015)

\section{Final thoughts and the Future of Generalist Writing Centres in Canada}

The aim of this paper was to take a deeper look into what might be a common writing centre tutoring session between two individuals in different disciplines and levels of study. Xiaoli's and Catherine's reflections point to one of the possible roles of generalist writing centre tutors. Certain conditions might have worked as an advantage for this particular session to work well, such as the fact that it was a braining storming session. A different interaction might have taken place had Xiaoli brought in a written draft with her, or in a completely different session, if Catherine had to tutor a student in the sciences on a lab report. For Xiaoli, although she did not consider the generic writing strategies helpful, the active engagement of Catherine, who pointed out new connections, helped her overcome her writer's block.

When asked about her perceived role as a writing centre tutor in our interview, Catherine touched upon the differences between specialist and generalist tutoring:

Okuda: $\quad$ So what do you think your role is as the tutor? Because, I don't think you're a teacher, right?

Catherine: No because a teacher implies some kind of expert knowledge not only how to write but what to write and obviously I can't fill that role in a lot of contexts, even in disciplines I have experience in, I'm not expert in my discipline at all! I'm just an undergrad, you know? So um, I think my role is to be a sounding board for ideas? Uh, and to really share the writing strategy side of it. Sometimes I'm able to help students understand their course material and that's great I have no problem with that, but other times that's really not a role I can fill and it's more about communicating that stuff again as opposed to understanding it the first time. 
Volume 27, 2017

http://journals.sfu.ca/cjsdw

(Interview with Catherine, 03/30/2015)

Perhaps this "sounding board" is exactly what some confused writers in any discipline or level need and what generalist tutors can offer. Even though they might not have the disciplinary knowledge, they can be good listeners and organizers of the writer's ideas, which writers like Xiaoli could benefit from.

Even though discipline-specific tutoring might be an ideal practice, in creating a writing support serving various student needs, it is crucial to examine the role of both generalists and specialists and identify specific cases where each might be effective. If a university mainly offers generalist tutoring, it might be important to make accessible other discipline-specific writing support services, especially for graduate students. In addition, tutor training would benefit from discussions about the role of a tutor (what they can and cannot do) and strategies to approach unfamiliar writing, which are indispensable for successful tutoring (Summers, 2016). This could include sharing and learning disciplinary characteristics of research genres amongst tutors (Walker, 1998). In such training, the literature on the role of generalist tutors, summarized below, could provide great insight:

1. Tutors can ask students about assignment and refer them back to professor if they are uncertain. In turn, professors can clarify their intentions and convey their expectations better to students (Chanock, 2002; Powers \& Nelson, 1995).

2. Tutor's unfamiliarity with the topic can push students to explain and reconstruct their subject knowledge (Hubbuch, 1988; Summers, 2016).

3. As "an interested, disinterested other", tutors can offer a more comfortable environment for discussing writing compared to consultations with supervisors or instructors (Pemberton, 1995).

4. As an outsider, tutors may offer new perspectives and connections (Pemberton, 1995).

Discipline-specific support and writing centres as teaching units may be a goal, but examining the reality of on-the-ground generalist writing support in Canada, such as the tutoring session described above, gives us the opportunity to examine and improve current tutoring practises. Given the rich theoretical foundation of Canadian writing studies, more evidence-based research on the unique tutoring practices of writing centres would further 
Volume 27, 2017

http://journals.sfu.ca/cjsdw

benefit the community and improve university writing support in identifying what the centres are doing and what more they can offer.

\section{References}

Bruffee, K. A. (1995). Peer tutoring and the "conversation of mankind.” In C. Murphy \& J. Law (Eds.), Landmark essays on writing centers (pp. 87-98). New York, NY: Routledge.

Chanock, K. (2002). How a writing tutor can help when unfamiliar with the content: A case study. The WAC Journal, 13, 113-132.

Dinitz, S., \& Harrington, S. (2014). The role of disciplinary expertise in shaping writing tutorials. Writing Center Journal, 33(2), 73-98.

Giltrow, J. (2016). Writing at the centre: A sketch of the Canadian history. Canadian Journal for Studies in Discourse and Writing, 26, 11-24.

Graves, R. (1993). Composition in Canadian universities. Written Communication, 10(1), 72105 .

Graves, R. (2016). Statement on writing centres and staffing. Canadian Journal for Studies in Discourse and Writing, 26, 5-10.

Graves, R., \& Graves, H. (eds.). (2006). Writing centres, writing seminars, writing culture: Writing instruction in Anglo-Canadian universities. Winnipeg, MB: Inkshed Publications.

Hubbuch, S. (1988). A tutor needs to know the subject matter to help a student with a paper: Agree disagree not sure. Writing Center Journal, 8(2), 23-20.

Kiedaisch, J., \& Dinitz, S. (1993). "Look back and say 'so what”": The limitations of the generalist tutor. The Writing Center Journal, 14(1), 63-74.

Mackiewicz, J. (2004). The effects of tutor expertise in engineering writing: a linguistic analysis of writing tutors' comments. IEEE Transactions on Professional Communication, 47(4), 316-328.

Mohamad, M., \& Boyd, J. (2010). Realizing distributed gains: How collaboration with support services transformed a basic writing program for international students. Journal of Basic Writing, 29(1), 78-98.

North, S. M. (1984). The idea of a writing center. College English, 46(5), 433-446. doi:10.2307/377047

Paré, A. (2017). The once and future writing centre: A reflection and critique. Canadian Association for Studies in Discourse and Writing/Rédactologie, 27, 1-8. 
Volume 27, 2017

http://journals.sfu.ca/cjsdw

Pemberton, M. A. (1995). Rethinking the WAC/writing center connection. The Writing Center Journal, 15(2), 116-133.

Powers, J. K., \& Nelson, J. V. (1995). Rethinking writing center conferencing strategies for writers in the disciplines. The Writing Lab Newsletter, 2O(1), 12-15.

Smith, T. (2006). Recent trends in undergraduate writing courses and programs in Canadian universities. In R. Graves \& H. Graves (Eds.), Writing centres, writing seminars, writing culture: Writing Instruction in Anglo-Canadian Universities (pp. 319-370). Winnipeg, MB: Inkshed Publications.

Summers, S. (2016). Building expertise: The toolkit in UCLA's graduate writing center. The Writing Center Journal, 117-145.

Thonus, T. (2002). Tutor and student assessments of academic writing tutorials: What is "success"? Assessing Writing, 8(2), 110-134.

Walker, K. (1998). The debate over generalist and specialist tutors: Genre theory's contribution. The Writing Center Journal, 18(2), 27-46. 